\title{
Pengaruh Gaya Kepemimpinan Transformasional Dan Kompensasi Terhadap Kinerja Pegawai KPRI Sejahtera Madiun
}

\author{
Windy Rizki Amalia ${ }^{1}$, Muhammad Imron $^{2}$, Hartirini Warnaningtyas ${ }^{3}$ \\ ${ }^{1}$ Program Studi Manajemen, Universitas Merdeka Madiun, Jl Serayu 70, Kota Madiun, 63133 \\ Email: windyamalia652@gmail.com \\ ${ }^{2}$ Program Studi Manajemen, Universitas Merdeka Madiun, Jl Serayu 70, Kota Madiun, 63133 \\ Email: muhammadimron@unmer-madiun.ac.id \\ ${ }^{3}$ Program Studi Manajemen, Universitas Merdeka Madiun, Jl Serayu 70, Kota Madiun, 63133 \\ Email: hartirini@unmer-madiun.ac.id
}

\begin{abstract}
This study aims to find out the partial and simultaneous influence of transformational leadership style variables and compensation on the performance of KPRI Sejahtera Madiun employees. The population in this study was kpri Sejahtera Madiun employees. Sampling using saturated sampling techniques. Samples taken by 40 employees. Research instruments use questionnaires. In this study, the data used were primary data, namely questionnaires measured using Likert scale and analyzed using multiple linear regression analysis with SPSS program version 25.0. The results of the tests have shown that: (1) Transformational leadership styles partially affect employee performance variables. (2) Compensation partially affects employee performance. (3) Transformational leadership style and compensation jointly (simultaneously) affect employee performance.
\end{abstract}

Keywords —: Transformational Leadership Style; Compensation; Employee Performance.

\section{PENDAhUluaN}

Keberhasilan suatu organisasi dalam menjalankan roda kesuksesannya, tidak terlepas dari kinerja para pegawainya, baik dalam menjalankan tugas maupun fungsinya di dalam organisasi. Kinerja pegawai yang mumpuni di dalam organisasi, dapat menyelesaikan tugasnya serta mampu bekerja secara efektif dan efisien akan menjadi salah satu jaminan sukses bagi organisasi tempat mereka bekerja. Dengan meningkatnya kinerja pegawai di dalam organisasi maka pada akhirnya tujuan didirikannya koperasi ini dengan profit oriented dapat tercapai dengan baik. Kemakmuran organisasi serta para pegawainya dapat terwujud.

Gaya Kepemimpinan memiliki hubungan yang sangat erat terhadap kinerja pegawai, sehingga kinerja pegawai yang harus dicapai sangat berhubungan dengan gaya kepemimpinan yang diterapkan oleh pemimpin organisasi. Salah satu jenis gaya kepemimpinan yaitu gaya kepemimpinan transformasional. Menurut Mondiani (2012), gaya kepemimpinan transformasional adalah kemampuan untuk memberikan inspirasi dan memotivasi para pengikutnya untuk mencapai hasil-hasil yang lebih besar daripada yang direncanakan secara orisinil dan imbalan internal. Gaya kepemimpinan transformasional cenderung memfokuskan diri pada penyelesaian tugas-tugas untuk memotivasi agar bawahan melakukan tanggung jawab mereka, menyamakan visi dan misi masa depan, dengan kecerdasan emosional serta hubungan manajemen yang baik bagi pegawai, maka akan terjadi iklim kerja yang kondusif, efektif serta efisien dalam menjalankan setiap tugas dan fungsinya masing-masing.

Tidak hanya gaya kepemimpinan yang mempunyai peranan dalam menghasilkan kinerja karyawan yang baik, demikian pula dengan kompensasi. Pegawai yang merasa kurang puas biasanya tingkat ketidakhadiran cenderung tinggi, mereka akan sering tidak hadir bekerja dengan berbagai alasan, bisa saja alasan yang mereka gunakan tidak logis dan subjektif.

Kompensasi dapat menjadi ukuran kualitas pekerjaan yang telah dilakukan dan diberikan pegawai kepada organisasi. Di mana hal ini dapat dijadikan faktor untuk memotivasi pegawai dalam meningkatkan kinerja agar mendapat kompensasi sesuai yang diharapkan. Jika pegawai termotivasi untuk meningkatkan kompensasi yang akan didapatkan, secara otomatis pegawai juga harus meningkatkan kinerjanya. Oleh karena itu, perhatian organisasi terhadap pengaturan kompensasi secara rasional dan adil sangat diperlukan. Bila pegawai memandang pemberian kompensasi tidak memadai, maka kinerja mereka cenderung menurun dan tidak dapat maksimal sehingga mengakibatkan tujuan organisasi sulit untuk tercapai.

Berdasarkan hasil survey, permasalahan yang terjadi terkait dengan kinerja saat ini yaitu terletak pada kurang optimalnya kinerja yang diberikan pegawai terhadap organisasi. Untuk lebih memaksimalkan kinerja pegawai tersebut, KPRI Sejahtera Madiun perlu meninjau kembali proses pemberian motivasi melalui pemberian kompensasi kepada pegawainya. Kinerja pegawai akan berjalan dengan efektif apabila didukung dengan gaya kepemimpinan dan kompensasi yang baik.

Koperasi Pegawai Negeri Republik Indonesia (KPRI) Sejahtera Madiun merupakan sebuah lembaga usaha yang berbadan hukum, KPRI Sejahtera Madiun sebagai salah satu koperasi dengan kompetensi yang tinggi diantara koperasi-koperasi lainnya dirasa perlu meningkatkan kinerja pegawai mereka melalui proses motivasi yang diwujudkan dengan pemberian kompensasi dan pada akhirnya nanti diharapkan mampu meningkatkan kinerja pegawainya. Peningkatan kinerja tersebut dapat 
Website : http://ekomaks.unmermadiun.ac.id/index.php/ekomaks

meningkatkan pula kinerja koperasi secara keseluruhan, yang dapat menjadi nilai tawar bagi KPRI Sejahtera Madiun untuk bersaing dengan koperasi lainnya.

\section{Rumusan Masalah}

1. Apakah gaya kepemimpinan transformasional berpengaruh terhadap kinerja pegawai KPRI Sejahtera Madiun?

2. Apakah kompensasi berpengaruh terhadap kinerja pegawai KPRI Sejahtera Madiun?

3. Apakah gaya kepemimpinan transformasional dan kompensasi secara simultan berpengaruh terhadap kinerja pegawai KPRI Sejahtera Madiun?

\section{TINJAUAN TEORITIS}

\section{A. Gaya Kepemimpinan Transformasional}

Menurut Artana (2012), kepemimpinan merupakan sifat, karakter atau cara seseorang dalam upaya membina dan menggerakkan seseorang atau sekelompok orang agar mereka bersedia, berkomitmen dan setia untuk melaksanakan kegiatan sesuai dengan tugas dan tanggung jawabnya untuk mewujudkan tujuan perusahaan yang telah di tetapkan sebelumnya. Mondiani (2012) mengartikan kepemimpinan transformasional sebagai kemampuan untuk memberikan inspirasi dan memotivasi para pengikutnya untuk mencapai hasil-hasil yang lebih besar daripada yang direncanakan secara orisinil dan untuk imbalan internal. Hal ini senada dengan teori Robbins \& Judge (2015), kepemimpinan transformasional adalah pemimpin yang menginspirasi para pengikutnya untuk mengesampingkan kepentingan pribadi mereka demi kebaikan organisasi dan mereka mampu memiliki pengaruh yang luar biasa pada diri para pengikutnya.

\section{B. Kompensasi}

Menurut Hasibuan (2014), kompensasi adalah semua pendapatan yang berbentuk uang, barang langsung atau tidak langsung yang diterima pegawai sebagai imbalan atas jasa yang diberikan kepada perusahaan. Kompensasi dalam bentuk uang atau lainnya, dapat berupa gaji, upah, bonus, insentif, dan tunjangan lainnya, seperti tunjangan kesehatan, tunjangan hari raya, uang makan, uang cuti, dan lain-lain.

\section{Kinerja}

Kinerja merupakan hasil yang dicapai seseorang berdasarkan persyaratan-persyaratan pekerjaan, persyaratan biasa disebut dengan standar kerja, yaitu tingkat yang diharapkan suatu pekerjaan tertentu untuk dapat diselesaikan dan diperbandingkan atas tujuan atau target yang ingin dicapai (Bangun, 2012).

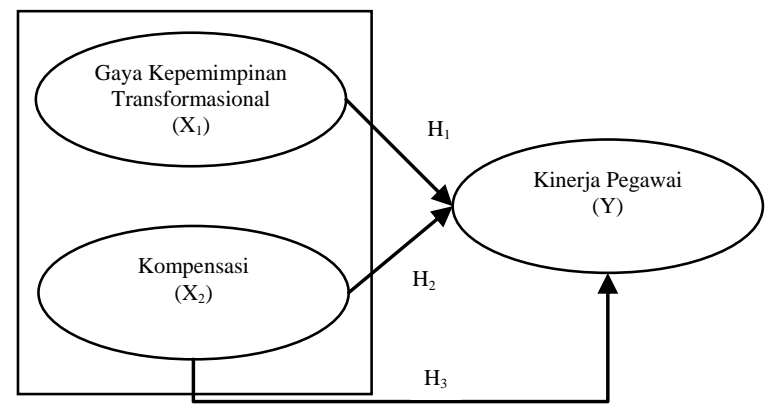

Gambar 1. Kerangka Pemikiran

Hipotesis penelitian ini adalah sebagai berikut:

1. Gaya kepemimpinan transformasional berpengaruh terhadap kinerja pegawai KPRI Sejahtera Madiun.

2. Kompensasi berpengaruh terhadap kinerja pegawai KPRI Sejahtera Madiun.

3. Gaya kepemimpinan transformasional dan kompensasi secara simultan berpengaruh terhadap kinerja pegawai KPRI Sejahtera Madiun.

\section{III.METODE PENELITIAN}

\section{A. Populasi dan Sampel}

Populasi dalam penelitian kuantitatif ini adalah seluruh pegawai KPRI Sejahtera Madiun. Jumlah populasi sebanyak 40 orang pegawai KPRI Sejahtera Madiun. Sehingga dalam pengambilan sampel menggunakan teknik sampling jenuh. Sampel jenuh adalah teknik penentuan sampel dengan cara mengambil seluruh anggota populasi sebagai responden atau sampel (Sugiyono, 2016). 
Website : http://ekomaks.unmermadiun.ac.id/index.php/ekomaks

\section{B. Indikator Variabel Penelitian}

1. Gaya Kepemimpinan Transformasional $\left(\mathrm{X}_{1}\right)$

Gaya kepemimpinan yang digunakan untuk menilai dalam penelitian ini adalah gaya kepemimpinan transformasional dengan menggunakan indikator yang dikembangkan oleh Robbins (2010), yaitu; charisma, motivasi inspiratif, stimulasi intelektual, dan perhatian yang individual.

2. Kompensasi $\left(\mathrm{X}_{2}\right)$

Adapun indikator yang dipakai dalam penelitian ini menggunakan indikator yang dikembangkan oleh Panggabean dalam Sutrisno (2010), yaitu; gaji, tunjangan, insentif, dan fasilitas.

3. Kinerja Pegawai $(\mathrm{Y})$

Kinerja dalam penelitian ini diukur dengan menggunakan indikator yang dikembangkan oleh Setiawan \& Dewi (2014), yaitu; ketepatan penyelesaian tugas, kesesuaian jam kerja, tingkat kehadiran, kerjasama antar karyawan, dan kepuasan kerja.

\section{Uji Instrumen Penelitian}

Jawaban dari responden dalam penelitian ini menggunakan pilihan jawaban dengan skala Likert 1-5, yang terdiri dari 1 (sangat tidak setuju), 2 (tidak setuju), 3 (netral), 4 (setuju), dan 5 (sangat setuju). Untuk menghasilkan kevalidatan data jawaban, instrument diuji menggunakan uji validitas dan reliabilitas. Uji validitas menggunakan Pearson Product Moment, sedangkan uji reliabilitas menggunakan Cronbach's Alpha.

\section{Teknik Analisa Data}

1. Uji Asumsi Klasik

Uji asumsi klasik dalam penelitian ini menggunakan uji normalitas, multikolinieritas, dan heterokedastisitas.

2. Analisis Regresi Linier Berganda

Pada analisis ini melihat uji koefisien determinasi $\left(\mathrm{R}^{2}\right)$ untuk melihat kemampuan model dalam menerangkan variasi variable terikat. Sedangkan untuk membuktikan hipotesis penelitian, menggunakan uji t (uji secara parsial) dan uji $\mathrm{F}$ (uji secara simultan).

\section{IV.ANALISIS DAN PEMBAHASAN}

\section{A. Hasil Uji Instrumen}

\section{Uji Validitas}

Berikut tabel hasil uji validitas menggunakan IBM SPSS Statistic versi 25:

Tabel 1. Rangkuman Hasil Uji Validitas Variabel $\mathrm{X}_{1}, \mathrm{X}_{2}$, dan $\mathrm{Y}$

\begin{tabular}{|c|c|c|c|c|}
\hline Variabel & Item Instrumen & r hitung & r tabel & Keterangan \\
\hline \multirow{4}{*}{ Gaya Kepemimpinan } & $\mathrm{X}_{1.1}$ & 0,821 & 0,320 & Valid \\
\cline { 2 - 5 } Transformasional $\left(\mathrm{X}_{1}\right)$ & $\mathrm{X}_{1.2}$ & 0,789 & 0,320 & Valid \\
\cline { 2 - 5 } & $\mathrm{X}_{1.3}$ & 0,927 & 0,320 & Valid \\
\cline { 2 - 5 } & $\mathrm{X}_{1.4}$ & 0,795 & 0,320 & Valid \\
\cline { 2 - 5 } & $\mathrm{X}_{1.5}$ & 0,825 & 0,320 & Valid \\
\cline { 2 - 5 } & $\mathrm{X}_{1.6}$ & 0,880 & 0,320 & Valid \\
\cline { 2 - 5 } & $\mathrm{X}_{1.7}$ & 0,886 & 0,320 & Valid \\
\hline \multirow{5}{*}{ Kompensasi $\left(\mathrm{X}_{2}\right)$} & $\mathrm{X}_{2.1}$ & 0,337 & 0,320 & Valid \\
\cline { 2 - 5 } & $\mathrm{X}_{2.2}$ & 0,681 & 0,320 & Valid \\
\cline { 2 - 5 } & $\mathrm{X}_{2.3}$ & 0,680 & 0,320 & Valid \\
\cline { 2 - 5 } & $\mathrm{X}_{2.4}$ & 0,854 & 0,320 & Valid \\
\cline { 2 - 5 } & $\mathrm{X}_{2.5}$ & 0,490 & 0,320 & Valid \\
\cline { 2 - 5 } & $\mathrm{X}_{2.6}$ & 0,378 & 0,320 & Valid \\
\cline { 2 - 5 } & $\mathrm{X}_{2.7}$ & 0,487 & 0,320 & Valid \\
\hline \multirow{5}{*}{ Kinerja Pegawai (Y) } & $\mathrm{Y}_{\cdot 1}$ & 0,657 & 0,320 & Valid \\
\cline { 2 - 5 } & $\mathrm{Y}_{\cdot 2}$ & 0,847 & 0,320 & Valid \\
\cline { 2 - 5 } & $\mathrm{Y}_{\cdot 3}$ & 0,854 & 0,320 & Valid \\
\cline { 2 - 5 } & $\mathrm{Y}_{\cdot 4}$ & 0,789 & 0,320 & Valid \\
\cline { 2 - 5 } & $\mathrm{Y}_{\cdot 5}$ & 0,787 & 0,320 & Valid \\
\cline { 2 - 5 } & $\mathrm{Y}_{\cdot 6}$ & 0,841 & 0,320 & Valid \\
\cline { 2 - 5 } & $\mathrm{Y}_{\cdot 7}$ & 0,820 & 0,320 & Valid \\
\cline { 2 - 5 } & & & &
\end{tabular}

Sumber: Data primer diolah, 2020

Berdasarkan Tabel 1 dapat disimpulkan bahwa seluruh instrumen penelitian pada variabel $\mathrm{X}_{1}, \mathrm{X}_{2}$, dan $\mathrm{Y}$ telah dinyatakan valid sehingga dapat dilanjutkan untuk uji berikutnya. 
Website : http://ekomaks.unmermadiun.ac.id/index.php/ekomaks

\section{Uji Reliabilitas}

Hasil pengujian reliabilitas terhadap variabel Gaya Kepemimpinan Transformasional $\left(\mathrm{X}_{1}\right)$, Kompensasi $\left(\mathrm{X}_{2}\right)$, dan Kinerja Pegawai (Y) dapat dilihat pada tabel berikut:

\begin{tabular}{|c|c|c|c|}
\hline Variabel & Cronbach's Alpha & $\begin{array}{c}\text { Batas Minimal Cronbach's } \\
\text { Alpha }\end{array}$ & Keterangan \\
\hline $\begin{array}{l}\text { Gaya Kepemimpinan } \\
\text { Transformasional }\left(\mathrm{X}_{1}\right)\end{array}$ & 0,928 & 0,60 & Reliabel \\
\hline Kompensasi $\left(\mathrm{X}_{2}\right)$ & 0,612 & 0,60 & Reliabel \\
\hline Kinerja Pegawai (Y) & 0,893 & 0,60 & Reliabel \\
\hline
\end{tabular}

Sumber: Data primer diolah, 2020

Berdasarkan Tabel 2. dapat disimpulkan bahwa seluruh instrument pada seluruh variabel telah memenuhi kriteria reliabilitas. Sehingga dapat dilanjutkan uji asumsi klasik.

\section{B. Hasil Uji Asumsi Klasik}

\section{Normalitas}

Berikut ini hasil uji normalitas dengan probability plot:

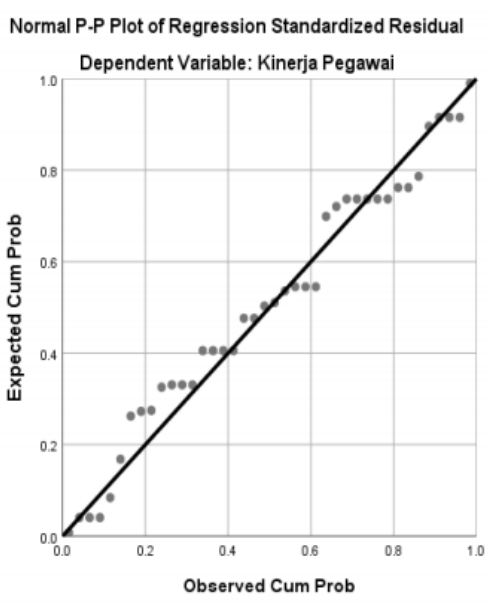

Sumber: Data primer diolah, 2020

Gambar 2. Hasil Uji Normalitas dengan Normal P-Plot

Berdasarkan Gambar 2. data menyebar di sekitar garis diagonal dan mengikuti arah diagonal. Dapat disimpulkan bahwa model regresi terdistribusi normal.

\section{Multikolinieritas}

Berikut tabel hasil uji multikolinieritas pada penelitian ini:

Tabel 3. Hasil Uji Multikolinieritas

\begin{tabular}{|c|c|c|c|c|c|c|c|}
\hline & & Coe & ficients $^{a}$ & & & & \\
\hline \multirow[b]{2}{*}{ Model } & \multicolumn{2}{|c|}{$\begin{array}{c}\text { Unstandardized } \\
\text { Coefficients }\end{array}$} & \multirow{2}{*}{$\begin{array}{c}\text { Standardized } \\
\text { Coefficients } \\
\text { Beta }\end{array}$} & \multirow[b]{2}{*}{$\mathrm{t}$} & \multirow[b]{2}{*}{ Sig. } & \multicolumn{2}{|c|}{ Collinearity Statistics } \\
\hline & $\mathrm{B}$ & Std. Error & & & & Tolerance & VIF \\
\hline \multirow{4}{*}{$\begin{array}{ll}1 \text { (Constant) } \\
\text { Gaya Kepemimpinan } \\
\text { Transformasional }\left(X_{1}\right) \\
\text { Kompensasi }\left(X_{2}\right) \\
\end{array}$} & 1.720 & 5.069 & & .339 & .736 & & \\
\hline & .403 & .117 & .453 & 3.453 & .001 & .790 & 1.266 \\
\hline & & & & & & & \\
\hline & .555 & 196 & .371 & 2.829 & .008 & .790 & 1.266 \\
\hline
\end{tabular}

Sumber: Data primer diolah, 2020 
Dari Tabel 3. dapat diketahui bahwa nilai VIF untuk gaya kepemimpinan transformasional sebesar 1,266 dan kompensasi sebesar 1,266. Karena untuk semua nilai VIF kurang dari 5, maka dapat disimpulkan bahwa pada model regresi tidak ditemukan adanya masalah multikolinieritas.

\section{Heterokedastisitas}

Berikut gambar hasil uji heterokedastisitas pada penelitian ini:

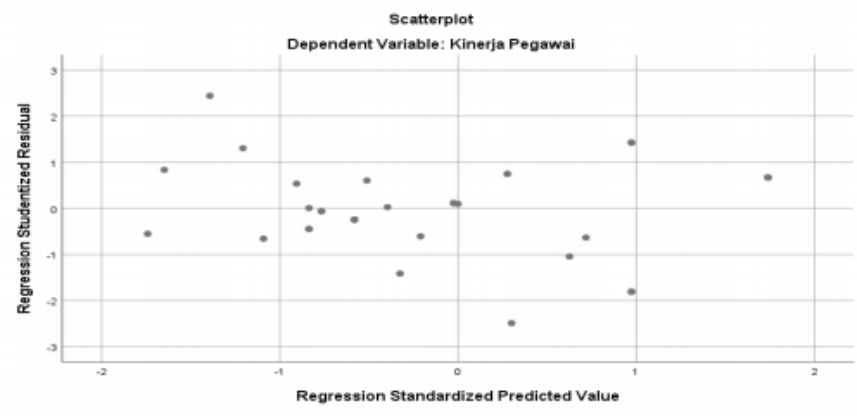

Sumber: Data primer diolah, 2020

Gambar 3. Hasil Uji Heterokedastisitas

Pada Gambar 3. memperlihatkan titik-titik menyebar secara acak, tidak membentuk pola yang teratur, serta tersebar di segala arah, baik di atas maupun di bawah angka 0. Dengan demikian dapat disimpulkan bahwa tidak terjadi masalah heteroskedastisitas, hingga model regresi yang baik dan ideal terpenuhi.

\section{Hasil Regresi Linier Berganda}

1 Koefisien Determinasi

Berikut tabel hasil uji koefisien determinasi:

Tabel 4. Hasil Uji Koefisien Determinasi $\left(\mathrm{R}^{2}\right)$

\begin{tabular}{|l|c|c|c|c|}
\hline \multicolumn{5}{|c|}{ Model Summary } \\
\hline Model & $\mathrm{R}$ & $\mathrm{R}$ Square & $\begin{array}{c}\text { Adjusted R } \\
\text { Square }\end{array}$ & $\begin{array}{c}\text { Std. Error of the } \\
\text { Estimate }\end{array}$ \\
\hline 1 & $.705^{\mathrm{a}}$ & \multicolumn{4}{|c|}{.497} & .470 & 2.24394 \\
\hline \multicolumn{5}{|c}{ a. Predictors: (Constant), Kompensasi, Gaya Kepemimpinan Transformasional } \\
\hline
\end{tabular}

Berdasarkan Tabel 4 dapat diketahui bahwa nilai Adjusted $R$ Square yaitu sebesar 0,470 atau 47\%. Artinya secara bersama-sama variabel gaya kepemimpinan transformasional dan kompensasi berpengaruh terhadap kinerja pegawai sebesar 47\%. Sedangkan variabel selain variabel dalam penelitian ini mempengaruhi variabel kinerja pegawai sebesar $53 \%$ seperti variabel sourcing channels dan placement (Mutmainah, Murseto, \& Rohmatiah, 2020), kepuasan kerja, dan lain sebagainya.

2 Uji t (secara parsial)

Berdasarkan pada Tabel 3, nilai signifikansi variabel $\mathrm{X}_{1}$ terhadap $\mathrm{Y}$ dan $\mathrm{X}_{2}$ terhadap $\mathrm{Y}$ lebih kecil dari 0,05 (0,001 dan 0,008). Dan nilai t hitung dari keduanya juga lebih besar dari nilai t tabel $(2,026)$. Hal ini menunjukkan bahwa hipotesis 1 dan 2 terbukti, variabel $\mathrm{X}_{1}$ (Gaya Kepemimpinan Transformasional) berpengaruh terhadap kinerja pegawai (Y) dan variabel $\mathrm{X}_{2}$ (Kompensasi) juga berpengaruh terhadap kinerja pegawai (Y).

3 Uji F (secara simultan)

Berikut tabel hasil uji $\mathrm{F}$ dalam penelitian ini:

Tabel 5. Hasil Uji F

\begin{tabular}{|c|c|c|c|c|c|c|}
\hline \multicolumn{7}{|c|}{ ANOVA $^{a}$} \\
\hline & & Sum of Squares & Df & Mean Square & $\mathrm{F}$ & Sig. \\
\hline \multirow[t]{3}{*}{1} & \multirow{3}{*}{$\begin{array}{l}\text { Regression } \\
\text { Residual } \\
\text { Total } \\
\end{array}$} & 184.095 & 2 & 92.047 & 18.280 & $.000^{\mathrm{b}}$ \\
\hline & & 186.305 & 37 & 5.035 & & \\
\hline & & 370.400 & 39 & & & \\
\hline \multicolumn{7}{|c|}{ a. Dependent Variable: Kinerja Pegawai } \\
\hline
\end{tabular}

Sumber: Data primer diolah, 2020 
Website : http://ekomaks.unmermadiun.ac.id/index.php/ekomaks

Nilai F tabel sebesar 3,25. Nilai F hitung sebesar 18,280 (lebih besar dari F tabel) dengan signifikansi lebih kecil dari 0,05 . Sehingga dapat disimpulkan bahwa hipotesis ketiga terbukti, kedua variabel independent yaitu gaya kepemimpinan transformasional $\left(\mathrm{X}_{1}\right)$ dan kompensasi $\left(\mathrm{X}_{2}\right)$ secara bersama-sama (simultan) berpengaruh terhadap variabel dependen yaitu kinerja pegawai (Y) secara nyata atau signifikan

\section{Pembahasan}

\section{Gaya kepemimpinan transformasional berpengaruh terhadap kinerja pegawai KPRI Sejahtera Madiun.}

Berdasarkan hasil analisis data diketahui variabel gaya kepemimpinan transformasional secara parsial berpengaruh signifikan terhadap kinerja pegawai. Hasil ini sesuai dengan penelitian yang telah dilakukan oleh Nashafa \& Raharjo (2016). Gaya kepemimpinan transformasional mempunyai dimensi kharismatik, stimulus intelektual, konsiderasi individual, serta motivate inspirasional. Jika pemimpin KPRI Sejahtera Madiun berhasil memengaruhi para pegawainya dengan visi dan misi yang dimiliki, menanamkan kharismanya, memotivasi dan menjadi inspirator, menstimulasi intelektual, kreatifitas dan menghargai para pegawai, maka dapat dipastikan para pegawai akan bekerja dengan baik, sungguh-sungguh dan loyal pada organisasi sehingga kinerja menjadi meningkat.

2 Kompensasi berpengaruh terhadap kinerja pegawai KPRI Sejahtera Madiun.

Berdasarkan hasil analisis data diketahui variabel kompensasi secara parsial berpengaruh signifikan terhadap kinerja pegawai. Hasil ini sesuai dengan penelitian yang telah dilakukan oleh Nashafa \& Raharjo (2016). Pada dasarnya kompensasi merupakan sesuatu yang diterima pegawai dari organisasi sebagai penghargaan hasil kerja dan kontribusinya terhadap organisasi. Pemberian kompensasi bertujuan untuk mendorong dan memungkinkan pegawai untuk meningkatkan ketrampilan, kemampuan dan kinerjanya secara optimal. Oleh sebab itu kompensasi sangat penting untuk menjaga kualitas kinerja pegawai KPRI Sejahtera Madiun.

3 Gaya kepemimpinan transformasional dan kompensasi secara simultan berpengaruh terhadap kinerja pegawai KPRI Sejahtera Madiun.

Kedua variabel bebas tersebut secara simultan berpengaruh terhadap kinerja pegawai, hal ini diakibatkan variabel bebas menjadi faktor kunci dari model analisis regresi linier berganda dalam penelitian ini. Variabel bebas memberikan kontribusi pengaruh yang besar terhadap kinerja pegawai KPRI Sejahtera Madiun.

\section{KESIMPULAN DAN SARAN}

\section{A. Kesimpulan}

Berdasarkan analisis data dan pembahasan hasil penelitian, maka dapat disimpulkan temuan penelitian sebagai berikut:

1. Gaya Kepemimpinan Transformasional berpengaruh signifikan terhadap Kinerja Pegawai KPRI Sejahtera Madiun

2. Kompensasi berpengaruh signifikan terhadap Kinerja Pegawai KPRI Sejahtera Madiun

3. Gaya Kepemimpinan Transformasional, dan Kompensasi berpengaruh secara simultan terhadap Kinerja Pegawai KPRI Sejahtera Madiun

\section{B. Saran}

Berdasarkan hasil penelitian, saran yang dapat disampaikan adalah sebagai berikut:

1. Pimpinan KPRI Sejahtera Madiun sebaiknya lebih sering untuk mengevaluasi kinerja pegawai agar sesuai dengan kebutuhan organisasi, dan meninjau kembali proses pemberian kompensasi kepada pegawai sesuai dengan kemampuannya.

2. Untuk meningkatkan kualitas atau mutu pekerjaan yang dilakukan pegawai KPRI Sejahtera Madiun, sebaiknya diadakan pelatihan dan pengembangan serta pemberian penghargaan bagi pegawai yang berprestasi.

3. Saran untuk peneliti yang akan dating adalah dapat memperluas populasi dan sampel serta dapat menambah variabelvariabel yang lain yang berkaitan dengan kinerja pegawai

\section{VI.DAFTAR PUSTAKA}

Artana, I. W. (2012). pengaruh Kepemimpinan, Kompensasi, dan Lingkungan Kerja Terhadap Kinerja Karyawan (Studi Kasus di Maya Ubud Resort \& Spa). Jurnal Manajemen, Strategi Bisnis, dan Kewirausahaan, 2(1), 66-80

Bangun, W. (2012). Manajemen Sumber Daya Manusia. Jakarta: Erlangga.

Hasibuan, M. S. (2014). Manajemen Sumber Daya Manusia. Jakarta: PT Bumi Aksara.

Mondiani, T. (2012). Pengaruh Kepemimpinan Transformasional dan Kompensasi Terhadap Kinerja Karyawan PT PLN (Persero) UPJ Semarang. Jurnal Administrasi Bisnis, 1(1), 35-40. Retrieved from https://doi.org/10.14710/jab.vlil.4317

Mutmainah, M., Murseto, T. D., \& Rohmatiah, A. (2020). Dampak Gender, Sourcing Channels, And Placement Terhadap Kinerja Karyawan. E-Journal Ekonomi dan Bisnis Universitas Udayana, 9(9), 879-898. doi:https://doi.org/10.24843/EEB.2020.v09.i09.p04

Nashafa, P., \& Raharjo, M. (2016). Pengaruh Gaya Kepemimpinan Transformasional Dan Kompensasi terhadap Kinerja Karyawan Dengan Motivasi Sebagai Variabel Intervening. Diponegoro Journal of Management, $5(3)$, 985-996. Retrieved from https://ejournal3.undip.ac.id/index.php/djom/article/view/14685

Robbins, S. P. (2010). Perilaku Organisasional, Jilid 1 dan 2 (Terjemahan). Jakarta: Salemba Empat. 
Website : http://ekomaks.unmermadiun.ac.id/index.php/ekomaks

Robbins, S. P., \& Judge, T. A. (2015). Perilaku Organisasi. Jakarta: Salemba Empat.

Setiawan, F., \& Dewi, A. (2014). Pengaruh Kompensasi Dan Lingkungan Kerja Terhadap Kinerja Karyawan Pada CV Berkat Anugrah. E-Jurnal Manajemen Universitas Udayana, 3(5). Retrieved from https://ojs.unud.ac.id/index.php/Manajemen/article/view/7951

Sugiyono. (2016). Metode Penelitian Kuantitatif, Kualitatif, dan R\&D. Bandung: Alfabeta.

Sutrisno, E. (2010). Manajemen Sumber Daya Manusia. Jakarta: Kencana. 